\title{
DISTRIBUTED FIBER OPTIC SENSING ON A LARGE TUNNEL CONSTRUCTION SITE: INCREASED SAFETY, MORE EFFICIENT CONSTRUCTION AND BASIS FOR CONDITION- BASED MAINTENANCE
}

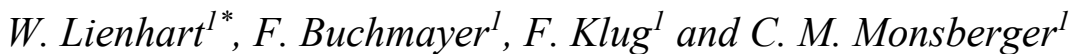 \\ ${ }^{I}$ Institute of Engineering Geodesy and Measurement Systems, Graz University of Technology, Graz, Austria \\ * Corresponding author
}

\begin{abstract}
The Semmering Base Tunnel is currently one of the largest tunnel construction sites in Central Europe. Two tunnel tubes, each $27.3 \mathrm{~km}$ in length, are being built from the portal and three intermediate construction sites. Each access point poses specific challenges and structural monitoring is a crucial element to ensure both economic and safe construction. In this paper we describe one of the most comprehensive distributed fibre optic sensing installations on a tunnel construction site worldwide. At the Semmering Base Tunnel, fibre optic sensing is used at every construction location to monitor tunnel linings, shafts, reinforced earth structures and pipelines. We also discuss the challenges posed by the installations and the results of long-term monitoring programmes. The installed monitoring systems will, furthermore, be used throughout the tunnel's expected 150 year operational lifetime. Unlike conventional sensors, fibre optic sensors do not comprise electric or moveable components at the measurement location. A longer lifetime can, therefore, be expected for fibre optic sensors which makes them promising candidates for condition-based maintenance of civil infrastructure.
\end{abstract}

\section{Introduction}

The Semmering Base Tunnel (SBT) is currently one of the main infrastructure projects in Austria. Two parallel $27.3 \mathrm{~km}$ tunnel tubes are being constructed between the town of Mürzzuschlag and the village of Gloggnitz. At present, all trains must cross the mountain ridge on the 165-year-old Semmering railway, comprising several short tunnels, viaducts, large height gradients and small curvature radii. Due to this historic track layout, train speed is low and only short freight trains with two engines can pass the mountain. The base tunnel will reduce the train journey time between Austria's capital Vienna and its second largest town Graz from $2 \mathrm{~h} 35 \mathrm{~min}$ to $1 \mathrm{~h} 50 \mathrm{~min}$ which is a reduction of $30 \%$. Rail goods traffic capacity will, moreover, be considerably increased because the low height gradient will enable deployment of long freight trains with only one engine.

To reduce construction time, the tunnel is being driven from the portal at Gloggnitz and from three intermediate construction access points in Göstritz, Fröschnitzgraben and Grautschenhof (Figure 1). Each construction site poses specific construction challenges which are discussed in detail in Gobiet et al. (2017).

Figure 1 Construction sites of the Semmering Base Tunnel (after Gobiet et al., 2017)

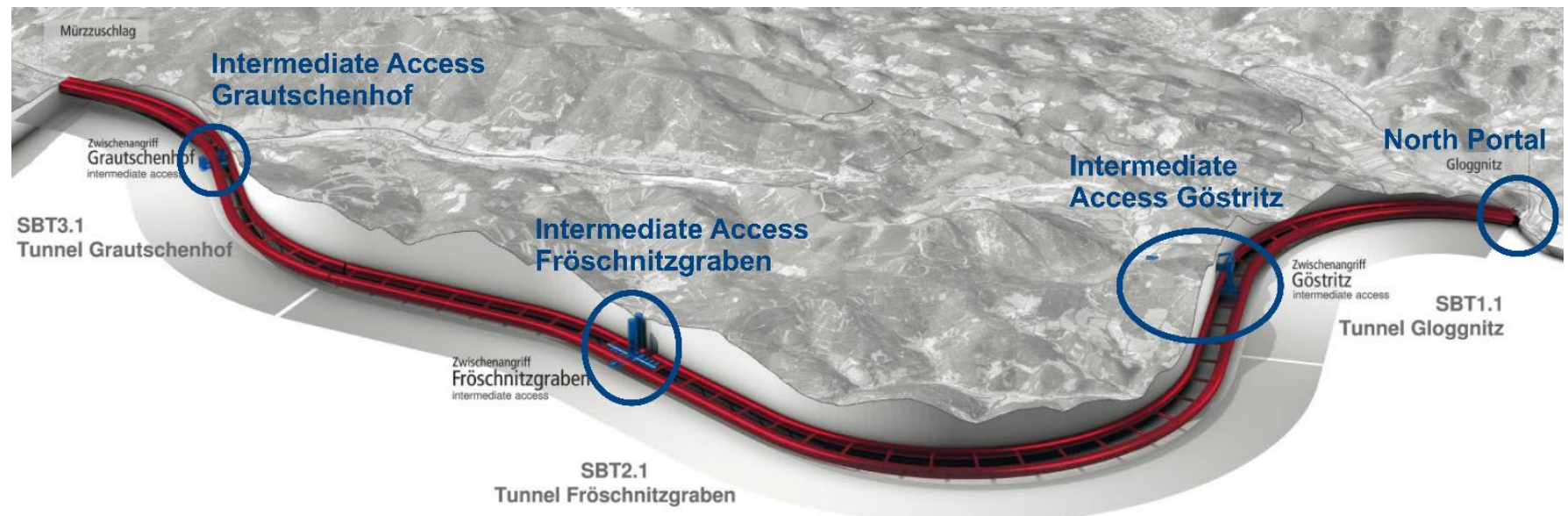


At the north portal and the Göstritz and Grautschenhof intermediate access points, conventional tunnelling based on the New Austrian Tunnelling Method (NATM), OeGG (2010), is being applied. At Fröschnitzgraben, the two tubes in the direction of Grautschenhof are also being constructed using NATM, whereas in the direction of Göstritz, two tunnel boring machines (TBMs) are in use. As well as conventional geotechnical sensors, distributed fibre optic sensing (DFOS) is being used at every construction site to increase worker safety, enable more efficient construction and to assess the structural integrity of the tunnel during its expected 150 year operational lifetime.

\section{Distributed fibre optic sensing}

\subsection{Background}

Fibre optic sensors have evolved significantly in recent years and are well suited for the monitoring of large linear structures such as bridges, railway tracks, pipelines and tunnels. Modern distributed fibre optic sensing systems can record strain and temperature changes with high accuracy and high spatial resolution over several kilometres and, thereby, enable early detection of local defects such as cracks and leakages. Monitoring of long term strain development can, furthermore, be used to guide condition-based maintenance.

Distributed fibre optic sensing systems use the natural back reflection of an optical fibre. If light with a certain wavelength, usually around $1550 \mathrm{~nm}$, is coupled into an optical fibre, linear (Rayleigh) and non-linear backscatter effects (Brillouin and Raman) occur (Figure 2). Raman backscattering is solely temperature sensitive, whereas Rayleigh and Brillouin backscattering is also sensitive to strain. Brillouin instruments can capture measurements over very long ranges (up to several tenths of kilometres) with a typical spatial resolution of $0.5 \mathrm{~m}$ to $2 \mathrm{~m}$ whereas Rayleigh instruments can only measure up to several tenths of metres but with a better spatial resolution in the range of a few millimetres. For more information about the principles of distributed fibre optic sensing see Hartog (2018). In this paper we focus on practical aspects and the achievable results in tunnelling applications.

Figure 2 Backscattered spectrum changes induced by variable temperature and strain (after Krohn et al., 2017)

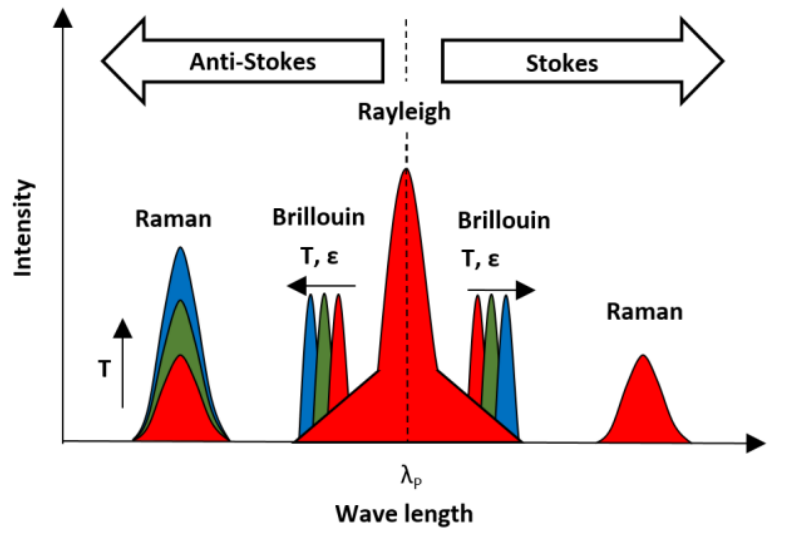

\subsection{Practical aspects of DFOS in tunnelling}

The fibre optic sensing cables must, first and foremost, tolerate the harsh tunnel construction environment. When, for instance, NATM is used, the outer tunnel lining is constructed with shotcrete which is high-pressure sprayed on to steel construction grids. The fibre optic sensing cable must be able to withstand this pressure and possible grid vibration. Sensing cables which are directly embedded during construction, therefore, consist of several protective layers. These layers must, moreover, be interlocking to ensure reliable strain transfer from the surface of the cable to the core of the optical fibre. Thirdly, because, as already mentioned above, Rayleigh and Brillouin backscattering signals are both strain and temperature sensitive, appropriate temperature compensation is crucial for reliable strain determination. A temperature sensing cable with a loose and non-tensioned fibre is very often installed parallel to the strain sensing cable with its rigid connection. If the spatial location of the two cables is known, the temperature sensing cable readings can be used to numerically correct the impact of temperature on the strain sensing cables. The corrected raw measurements, typically frequency shifts, must, lastly, be converted into strain readings and the characteristic curve relating frequency shift to strain must therefore be known. This curve is approximately linear but the slope coefficient differs between different cable types and sometimes also between different production batches of the same cable type, mandating individual calibration. An example of a cable calibration is provided in Monsberger et al. (2018b).

All of these aspects had to be taken into account for the fibre optic installations at the Semmering Base Tunnel as described in the next section. The monitoring task and the fibre optic implementation are described for each access point.

\section{Gloggnitz Portal}

\subsection{Monitoring of a shotcrete tunnel lining}

The idea underlying NATM is that the tunnel cross sections are cut out sequentially, i.e. first the top heading followed by the bench and invert. Following excavation of each section, an outer primary lining is applied using shotcrete (also referred to as sprayed concrete), supported by anchors and steel arches. This outer lining is generally flexible and allows deformation to occur to some extent. Deformation evolution is usually assessed by daily manual measurements using a total station (OeGG, 2014). These measurements deliver the required information, but are time consuming and thus only performed during the initial weeks following construction. Long-term terrain movements, erosion and recent tectonics could potentially change the mountain's equilibrium state during the tunnel's operational lifetime. To assess the longterm behaviour of the tunnel lining, new measurement techniques are evaluated at the Semmering Base Tunnel. Conventional methods, such as 3D point-wise geodetic deformation measurements or laser scanning are usually expensive, time consuming and often require an interruption of tunnel traffic. Distributed fibre optic sensing, on the other hand, enables remote tunnel monitoring after installation. In order to verify the robustness and the suitability of DFOS for 
the monitoring of the shotcrete lining of a tunnel, several cross sections of the Semmering Base Tunnel were equipped with sensing cables.

\subsection{Installation}

De Battitsta et al. (2015) reported the installation of distributed fibre optic sensing cables between the first and second layers of the sprayed concrete lining. In their application, the sensing cable was clamped every $0.5 \mathrm{~m}$ to the surface of the primary lining. We, in contrast, embedded the sensing cables in both layers of the shotcrete lining, which, advantageously, allows both strain changes in circumference direction and curvature changes to be derived.

For our instrumentation, we used cables from Solifos AG (formerly Brugg AG). In the installation of 2017, two BRUsens V3 cables were installed in one cross section to measure strain and temperature. This cable has a structured surface which ensures rigid bonding with the concrete along the entire cable length. One section of the cable was directly mounted to the reinforcement grid, whilst the other one was loosely installed in a cladding tube so as to be sensitive only to temperature effects. In this installation, all measurements were retrieved with a fibre optic instrument based on the Rayleigh principle with a spatial resolution of $1 \mathrm{~cm}$ (Monsberger et al., 2018a and Monsberger et al., 2018b).

Another installation was completed one year later in March 2018 in the second tunnel tube (Henzinger et al., 2018). One cable (BRUsens V3) was used to measure strain and a different cable type (BRUsens) to measure temperature. Both cables use a metal tube as a protective layer. The optical fibre in the temperature cable is, however, also embedded in a gel preventing strain transfer from the shotcrete to the fibre. This strain insensitivity was verified in laboratory tests during concrete beam load tests (Henzinger et al., 2018). Cables were first installed in the two concrete layers of the top heading. A few days later the bench and invert were also excavated at this cross section and sensing cables were again installed in both shotcrete layers.

Figure 3 Installation of sensing cables on the reinforcement grid of the bench and invert

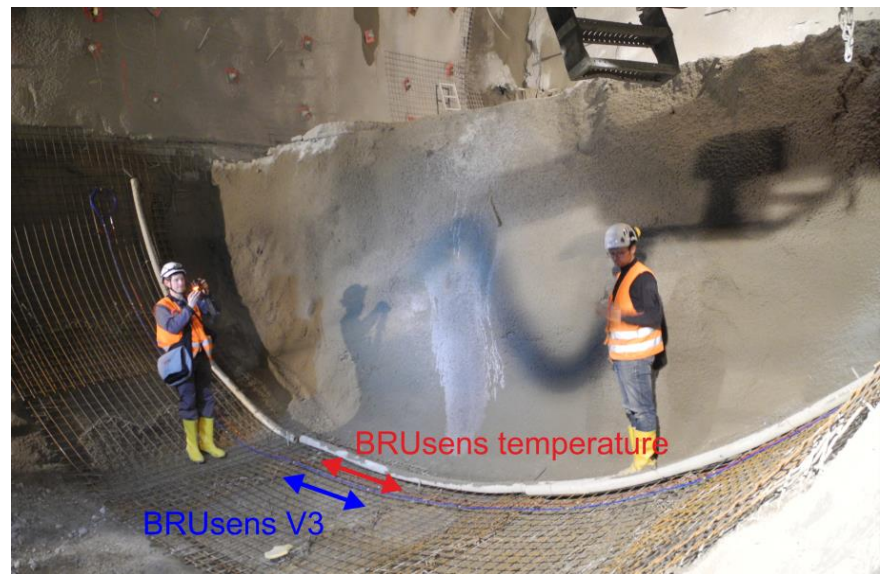

All cables were mounted directly on the reinforcement grids using cable ties (Figure 3 ). The spatial location of the cable in the tunnel coordinate system was then measured with a total station since knowledge of the exact location of the strain and temperature cables is crucial for reliable temperature compensation. The known 3D positions, furthermore, support data interpretation and comparison with other sensor data. To improve visualisation, 3D point clouds of the cross section were obtained by 3D laser scanning. Figure 4 shows the georeferenced point clouds and the measured cable positions.

Figure 4 Point cloud of the tunnel cross section and location of the sensing cables in both shotcrete layers

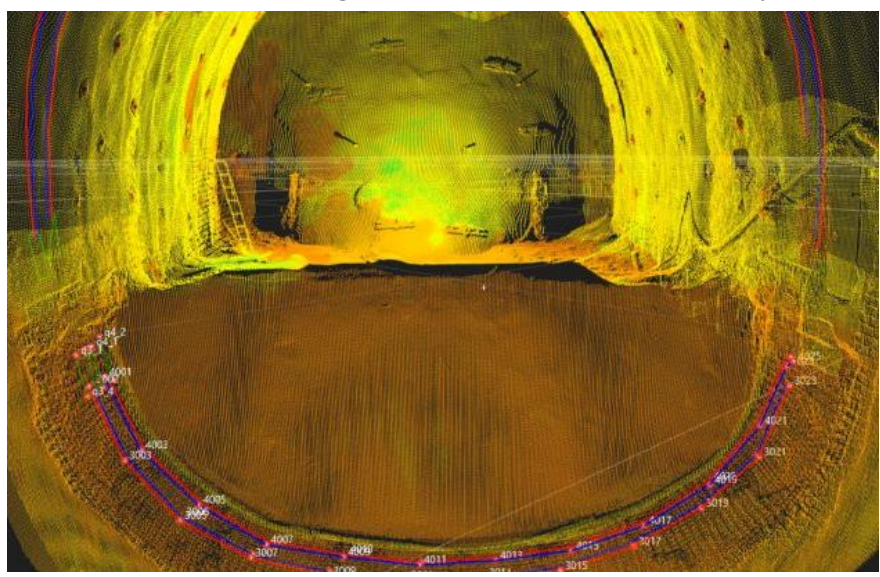

Shotcrete was sprayed following cable installation and performance of a functionality test. Figure 5 shows this process for the top heading. Scanning was performed before and after application of the first shotcrete layer and also following the application of the second layer. The actual thickness of the concrete layer can, hence, be determined from these 3D measurements.

Figure 5 Spraying of the second layer of shotcrete of the top heading

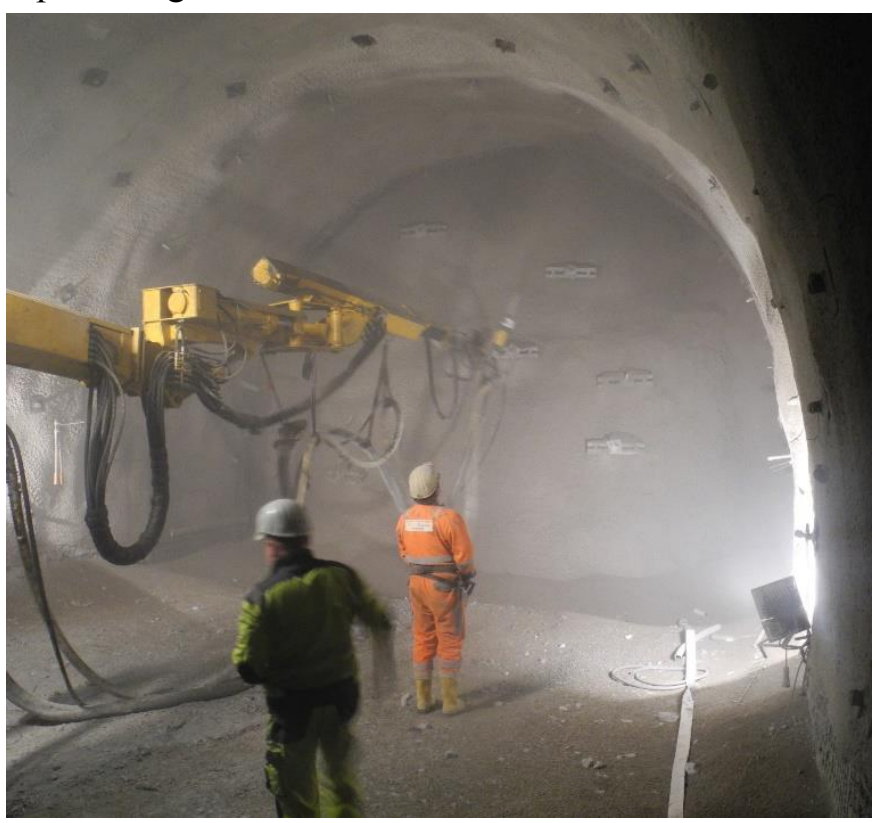




\subsection{Fibre optic measurements and results}

Fibre optic measurements commenced immediately after installation and the whole section was fully autonomously monitored with two measurements per hour for several weeks until the deformations decayed. The instrument was, therefore, placed in a robust metal box about $100 \mathrm{~m}$ behind the measurement section. Crucially, fibre optic measurements do not interfere with the construction process. Total station measurements, in contrast, usually require a setting-up of the instrument on a tripod in the construction area.

Following deformation stabilization, epoch-wise measurements were performed at monthly intervals. As already mentioned in the measurement section of the first tube, a Rayleigh backscattering instrument from LUNA was used, and for the installation in the second tube a Brillouin instrument from FibrisTerre.

Figure 6 shows strain development at five selected locations, as measured with the Brillouin instrument. For the crown point the results of both layers are displayed. For the left and right shoulder, as well as for the bottom point, only the outer layer results are shown. It can be clearly seen that the excavation of the bench and invert initiated new deformations of already stabilized areas. This behaviour is, though, expected and, overall, the deformations found in this cross section lie within acceptable limits. At both this cross section and the fibre optic cross section of the first tube, the distributed fibre optic measurement results are in good agreement with the results of other point sensors, for instance fibre Bragg gratings (Henzinger et al., 2018) or vibrating wire sensors (VWS) and total station measurements (Monsberger et al., 2018a). Unlike point sensors, however, distributed fibre optic sensors inherently allow information to be captured along the entire fibre, leaving no blind spots and even enabling detection of local lining failure. This benefit is also a motivation for the monitoring installation at the Göstritz intermediate access point.

Figure 6 Strain development at five locations in February 2018

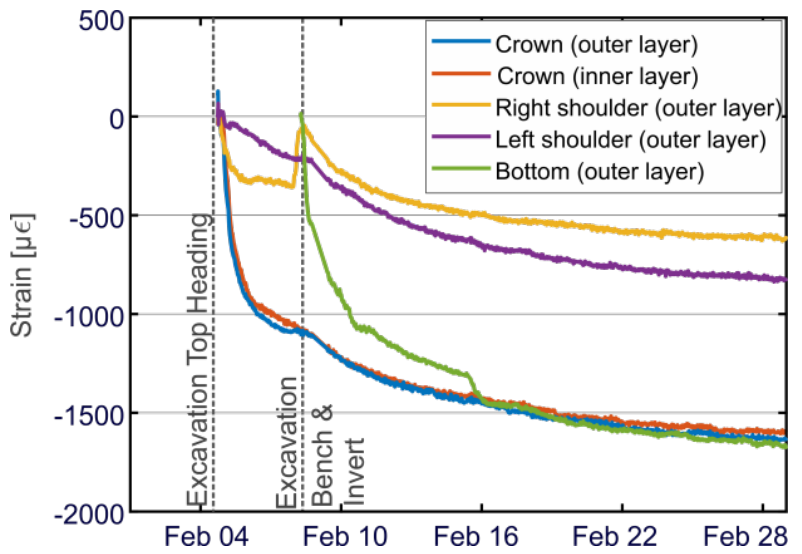

\section{Göstritz access point}

\subsection{Shaft monitoring}

At the Göstritz intermediate access point, a complex construction was required to reach the planned altitude of the future railway tunnels. A more than $1 \mathrm{~km}$ long horizontal tunnel was driven from the surface into the mountain, at the end of which, a massive cavern system was built to enable the construction of two approx. $240 \mathrm{~m}$ deep shafts and to host the logistics for work force, machine and material transport up and down the shafts. The complexity of this tunnel construction site is depicted in Figure 7 and described in detail in Wagner et al. (2015) and Wieland et al. (2018).

Figure 7 Access tunnel, caverns and shafts (blue) at the Göstritz access point of the Semmering Base Tunnel (red) after Wieland et al. (2018)

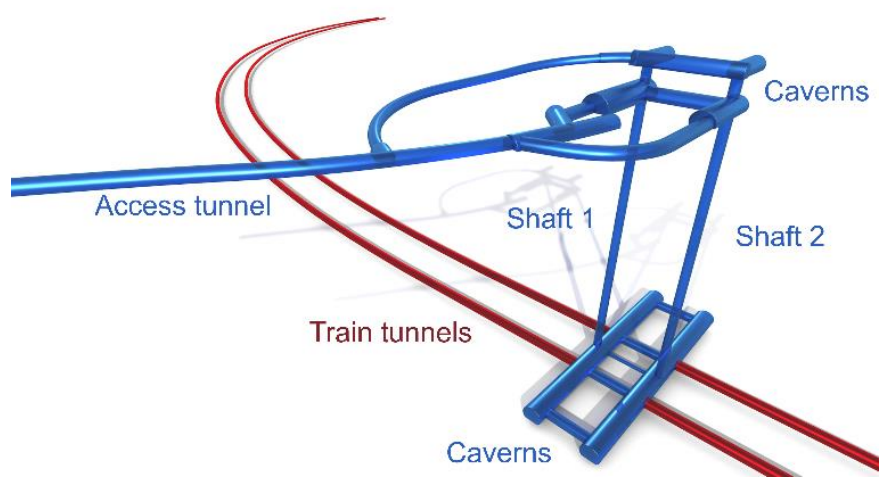

Previous test boreholes revealed the geological circumstances in this area to be very challenging. Water intrusion is possible at various locations due to many geological fault sections. Critical, for instance, is the potential for an erosion of earth and rock material caused by water flow behind the shotcrete lining of the shafts. A geotechnical monitoring program was set-up to detect any degradation of the stability of the shaft walls at an early stage. Conventional 3D displacement measurements of the shafts walls with total stations are difficult due to very steep and almost vertical sightings. Total station measurements are, moreover, time consuming and hard to manage in shafts with water intrusion. They also interrupt the shaft sinking process and interfere with the operation of the completed shafts. Total station targets, furthermore, become dirty within a short time in shafts and are problematic to clean. It was, therefore, decided to use a distributed fibre optic system embedded in the shotcrete linings of the shafts.

\subsection{Installation}

Based on the geological situation, five horizontal cross sections with depths ranging from 177 to $229 \mathrm{~m}$ below the cavern were chosen for monitoring (Figure 8). Strain and temperature cables were installed in both layers of the shotcrete linings of every cross section, in each case configured as a loop with $70 \mathrm{~m}$ length $(35 \mathrm{~m}$ strain and temperature sensitive and $35 \mathrm{~m}$ only temperature sensitive). 
Figure 8 Layout (not to scale) of the distributed fibre optic measurement system at the Göstritz access point

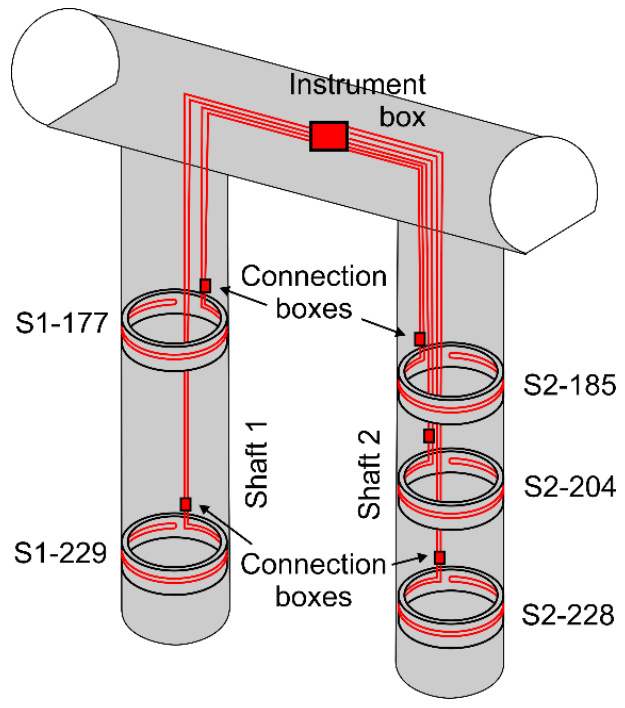

A challenging aspect of this installation was the small working space in the shaft (Figure 9) due to the small diameter of $8 \mathrm{~m}$, and the amount of water, which constantly flowed along the shaft walls and dropped down. Waterproofing of the connection box and its surroundings was hence crucial during the installation process. The position of the fibre optic sensing cables was again measured with a total station.

Figure 9 Vertical view down the shaft during construction at Göstritz

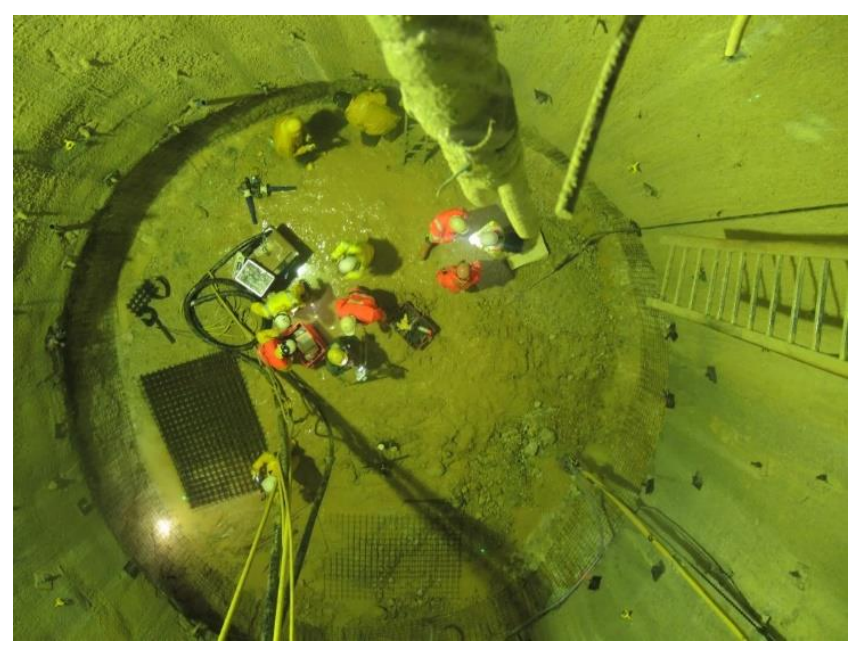

Each monitoring section has a connection box from which multi-fibre leading cables (Figure 8) establish the connection to a central measurement location (Figure 10) at the cavern at the top of the shafts. Measurements can, thus, be undertaken without any interference with the construction process.

Epoch-wise measurements are currently carried out every month with a FibrisTerre Brillouin instrument to gain a better understanding of the long term behaviour of the shaft linings. If one of these measurements indicates significant changes, the set-up is in place to enable a switch from epoch-wise measurements to continuous measurements.
Figure 10 Cavern at Göstritz

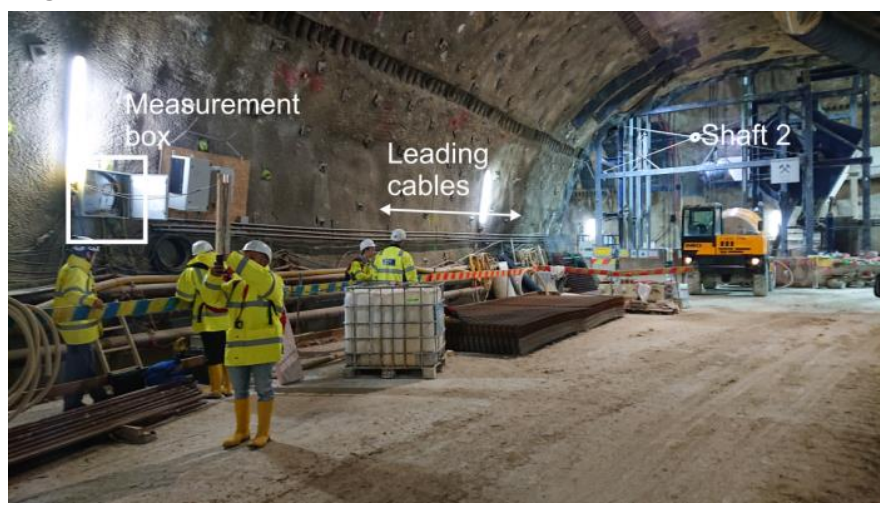

\subsection{Results}

The Brillouin spectrum was recorded at every measurement epoch with a spatial resolution of $0.5 \mathrm{~m}$ and a sampling interval of $0.05 \mathrm{~m}$. The spectrum of one cross section is shown in Figure 11. As mentioned above, about $70 \mathrm{~m}$ of sensing cables were installed in every shotcrete layer. The different base frequencies of the different cable types (strain and temperature) are clearly visible. Greater variation in the Brillouin frequencies along the strain cables than along the temperature cables can, furthermore, be seen due to the strain development of the lining.

\section{Figure 11 Brillouin spectrum of cross section S2-185} recorded on 23.06.2018

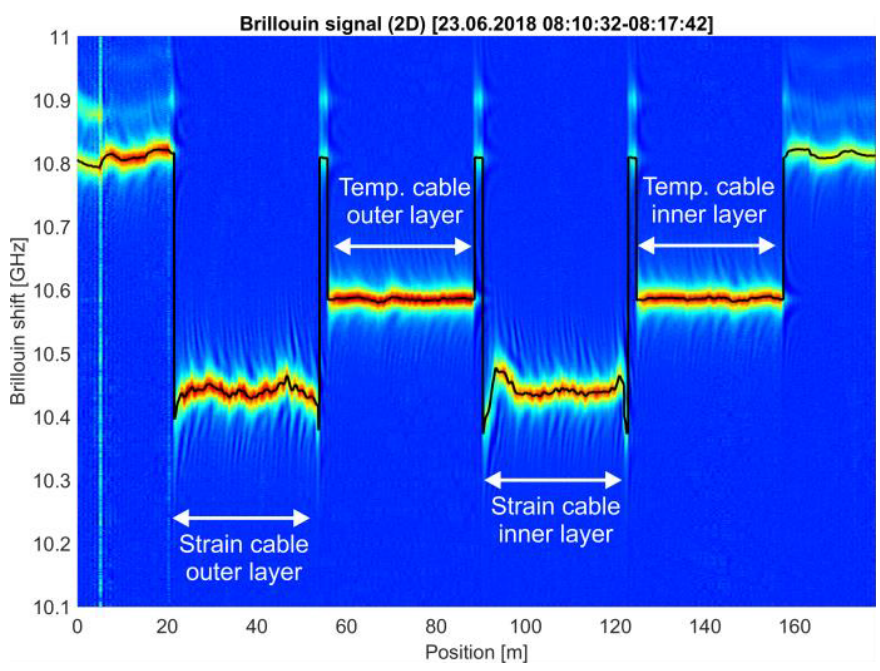

In the processing step, the temperature impact on the strain sensing cables was numerically compensated using the data from the corresponding positions of the temperature cable. To support data interpretation, it is beneficial to display the strain results along the tunnel lining. This is exemplified using the S2-228 strain values in Figure 12 which shows the strain changes with respect to the zero measurement taken on 21.08.2018. It can be seen that the strain change is not homogenous along the entire cross section: almost no strain changes occur, for example, at the 12 o'clock position. A reduction in the velocity of the strain changes is, furthermore, noteworthy. Within the three weeks between 27.08.2018 and 19.09.2018 the strain decreases significantly more than during the three weeks between 19.09.2018 and 11.10.2018. Overall, 
a maximum strain decrease of about $1000 \mu \mathrm{m} / \mathrm{m}$ was observed for this cross section.

Figure 12 Strain distribution along the inner layer of the shotcrete lining of section S2-228 at different dates with respect to the zero measurement on 21.08.2018

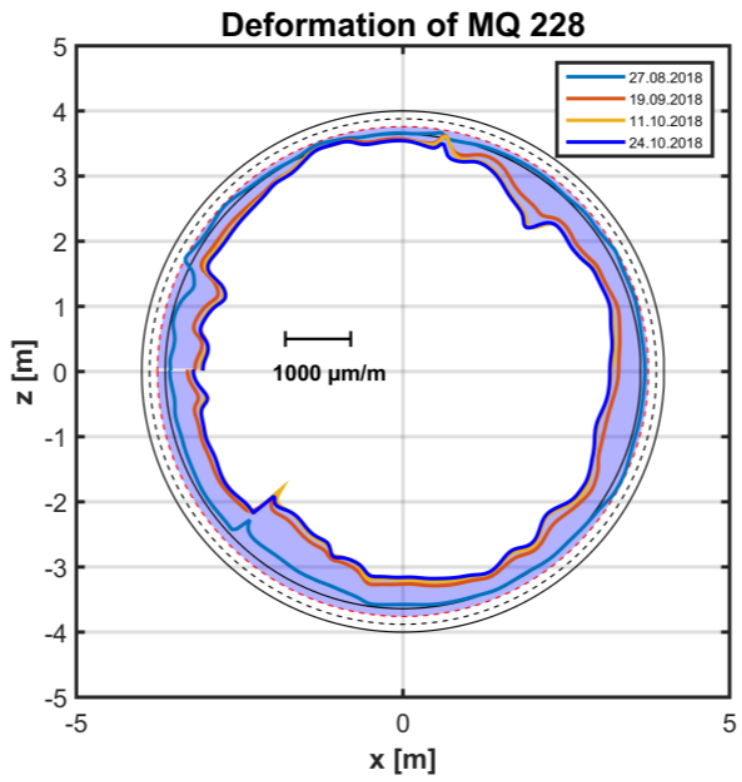

The installed measurement system is intended to be used for the next eight years until tunnel construction is completed and after which the shafts will be refilled. Reliable operation of distributed fibre optic systems for several years or even longer was already previously demonstrated at the Semmering Base Tunnel Fröschnitzgraben access point.

\section{Fröschnitzgraben access point}

\subsection{Longsgraben disposal site}

A legal environmental requirement for the construction of the Semmering Base Tunnel was that most of the excavation material must remain in the Semmering mountain area. The Longsgraben valley was selected as a central disposal site to enable compliance. Material from the Fröschnitzgraben access point (Nipitsch and Pacher, 2017) is transported to the disposal site with a conveyor belt, whilst material from the other intermediate access points is trucked there.

Figure 13 Relocation of a stream using a reinforced earth structure in the Longsgraben valley

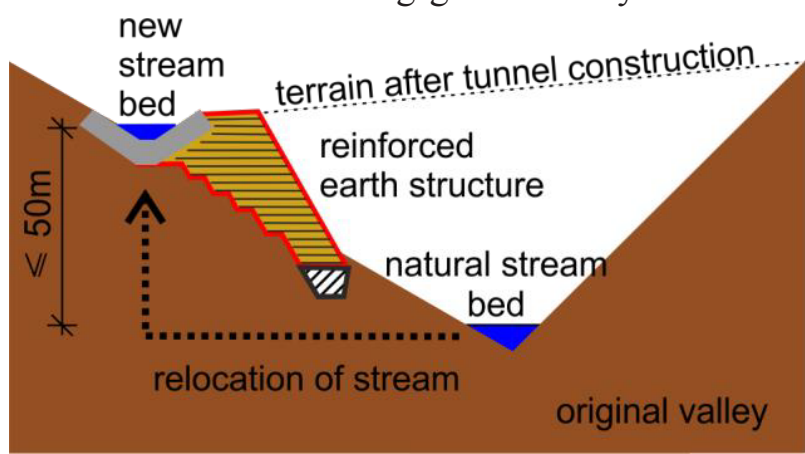

To render the inhabited mountain valley a suitable landfill area, trees had to be felled and the stream at the bottom of the valley relocated to a higher level which will form the new valley bottom following complete filling of the disposal site with the tunnel excavation material (Figure 13). More detailed information concerning these preliminary works for the Semmering Base Tunnel can be found in Schuller et al. (2014).

The challenge in this case was to build a stable supporting structure for the new river bed whilst minimising capacity loss at the disposal site. To achieve this, a reinforced earth structure was selected. The slopes of the realized construction have an angle up to $75^{\circ}$ and a height of up to $25 \mathrm{~m}$. To assess the stability of the structure, deformations are measured to bireflex targets on the surface of the structure. These measurements are, however, only sensitive to surface displacements and do not provide information about internal strain distribution. Conventional geodetic measurements were, thus, complemented with internal DFOS measurements.

\subsection{Installation}

To obtain reliable information about the behaviour of the structure, four cross sections were equipped at different heights with fibre optic sensing cables. At each section, the sensing cables were directly connected to the geo-grids with specially designed and tested anchors. A loop-configured sensing system was chosen. In the forward loop of each level, the sensing cable was pre-strained to also capture negative strain, whereas the back-loop was laid without tensioning and was thus only sensitive to temperature changes. All sensing cables were connected to one measurement loop with a length of about $2.5 \mathrm{~km}$ which can be measured from a single monitoring station (Figure 14).

Figure 14 Fibre optic measurement loop at the reinforced earth structure in the Longsgraben valley

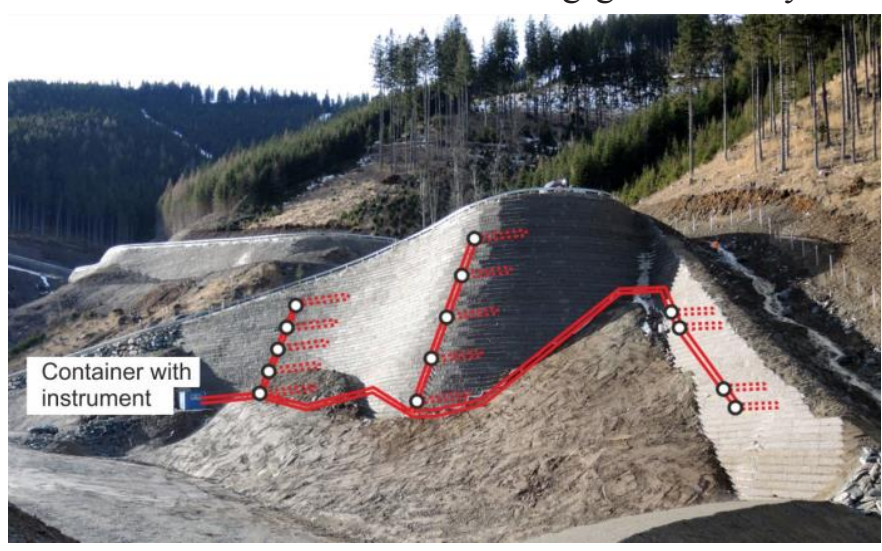

\subsection{Results}

Weekly measurements were carried out during the September 2013 construction phase to capture early strain evolution in the geo-grids. After construction, monitoring was continued with quarterly measurements and is still on-going. All measurements were performed with a Brillouin instrument from FibrisTerre. Moser et al. (2016) have already described strain development within the first year. 
Figure 15 Strain evolution of the geo-grid within the reinforced earth structure of level 3 of cross section 2
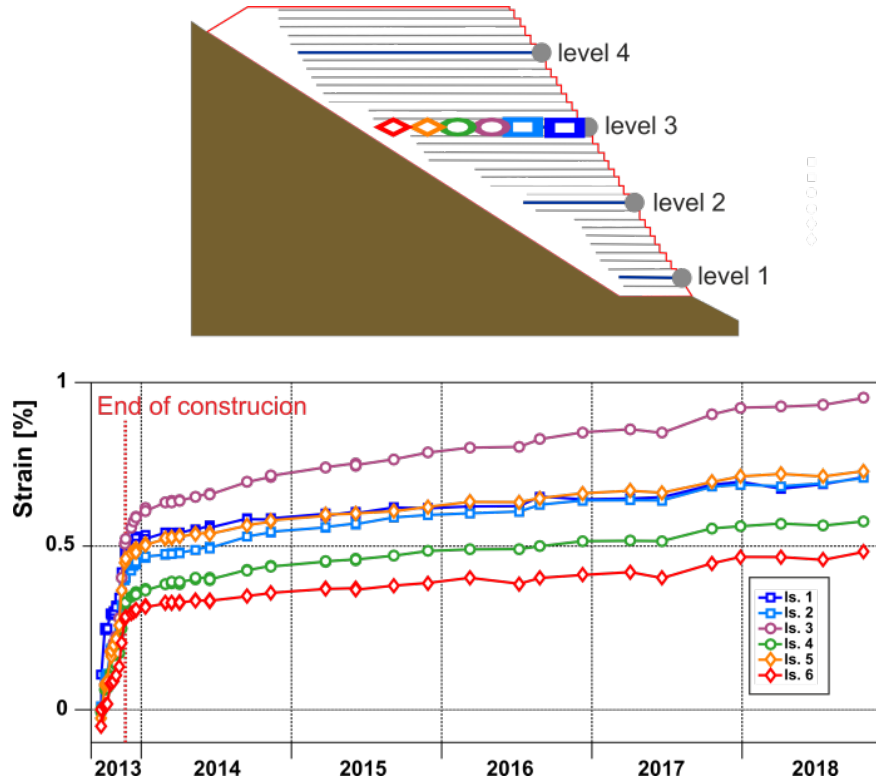

In this article, we show that strain within the geo-grid is still increasing even after five years. This is exemplified by the strain results for level 3 of cross section 2 as shown in Figure 15.

It can be seen that strain increased rapidly during construction and evolved into an almost linear increase with different gradients for different segments. At this level, strain is lowest in the rear of the structure, followed by the front side. The highest strains (approximately 1\%) occur in the central area of this level. It should be noted that whilst different levels exhibit different behaviour, strain increase with a small gradient can be generally seen at all levels. This highlights the importance of long-term measurements which can depict both initial deformations after construction and long term creep effects. To date, all described DFOS installations generated epoch-wise measurements or continuous measurements limited to a period of several weeks. The Semmering Base Tunnel, in contrast, also contains a continuous DFOS monitoring system with automated alarming.

\section{Grautschenhof access point}

\subsection{Pipeline monitoring}

Space is very limited at the final access point since, above ground, the entire construction site for the two tunnel tubes is sandwiched between a highway and a mountain slope. Access to the tunnel tubes is achieved via two $100 \mathrm{~m}$ deep shafts. A particular challenge was posed by a corridor of three gas pipelines which cross the construction area over a distance of $320 \mathrm{~m}$.
Figure 16 Layout of the Grautschenhof construction site (background image: (C) GIS-Steiermark, 2011)

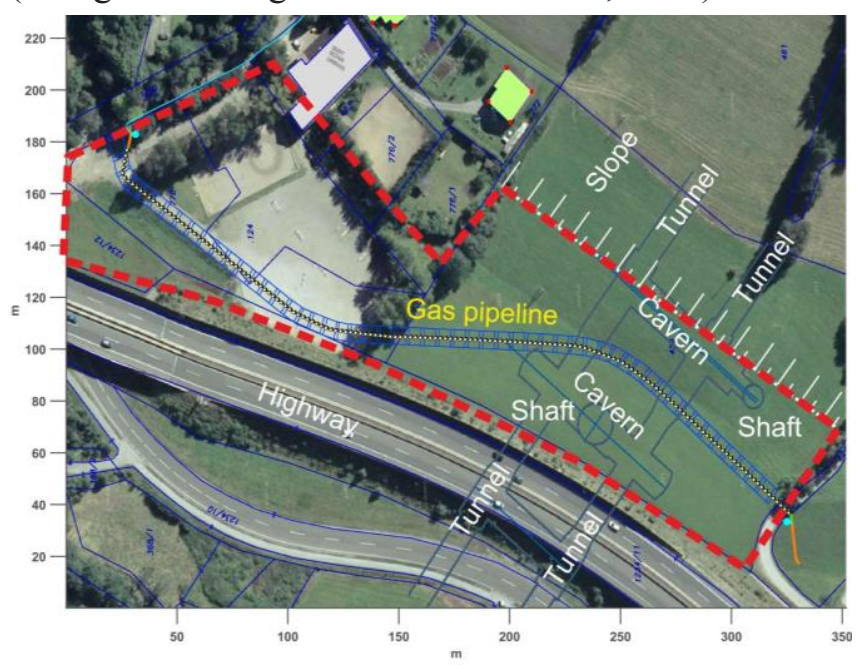

One of these is the main feed line for the region of Styria and uninterrupted operation is, thus, crucial. An overview of the complex situation at this access point is depicted in Figure 16 and also described in Klais et al. (2017). To enable immediate detection of any deleterious impacts on the pipelines, it was decided to install a fully automated permanent fibre optic monitoring system with automated alarming,

\subsection{Installation}

The three pipelines originally traversed the construction area along different paths. To provide sufficient space for the two access shafts, the two smaller pipelines $(0.15 \mathrm{~m}$ and $0.30 \mathrm{~m}$ diameters $)$ were placed next to the larger $(0.80 \mathrm{~m}$ diameter $)$ pipeline in order to locate all three pipelines within a single corridor. The open trench during the relocation can be seen in Figure 17.

Figure 17 Relocation of the pipelines at the Grautschenhof construction site

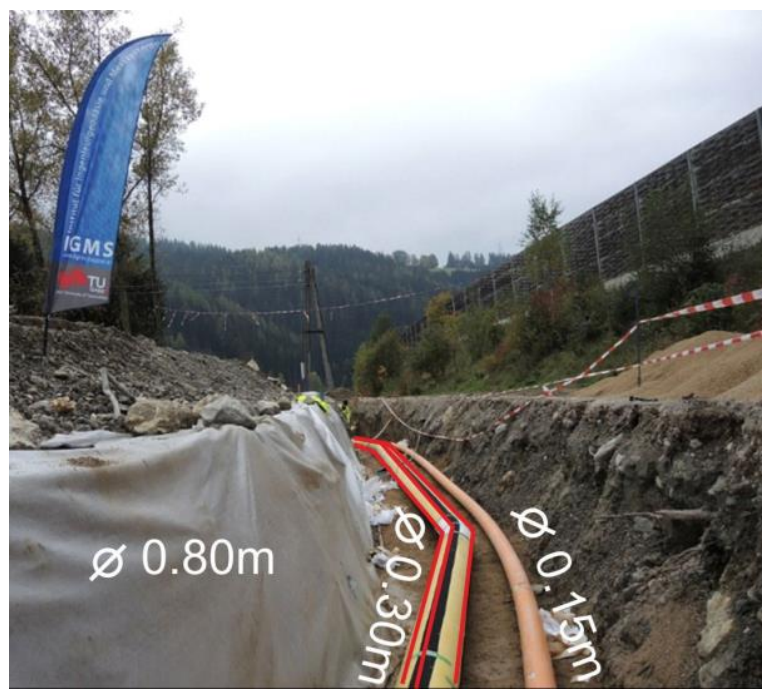


During the relocation process, three distributed fibre optic sensing cables were mounted on one of the pipelines. These cables were glued along the entire pipeline length at the positions 9, 12 and 3 o'clock as depicted in Figure 18. This configuration enables calculation of both average longitudinal strain and horizontal and vertical curvatures. A separate loose cable was, furthermore, installed parallel to the pipeline to enable temperature compensation. For the measurements, all cables were connected to create a loop which was extended with leading cables to a nearby building where the instrument rack with a combined BOTDA and BOTDR instrument from Omnisens is located. This significantly improves system robustness since, in the event of fibre breakage, the measurements can be changed from the loop set-up (BOTDA mode) to a single ended configuration (BOTDR mode).

Figure 18 Location of the sensing cables on the pipeline at Grautschenhof

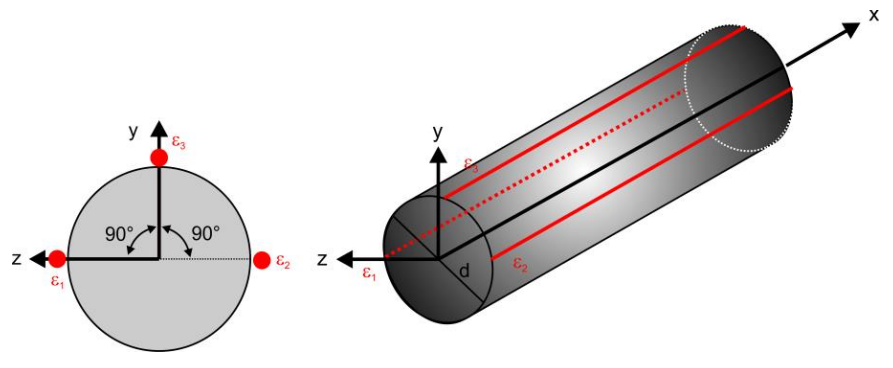

Figure 19 Construction site after installation of the fibre optic sensing cables in 2016 (top) and in winter 2018 (bottom)

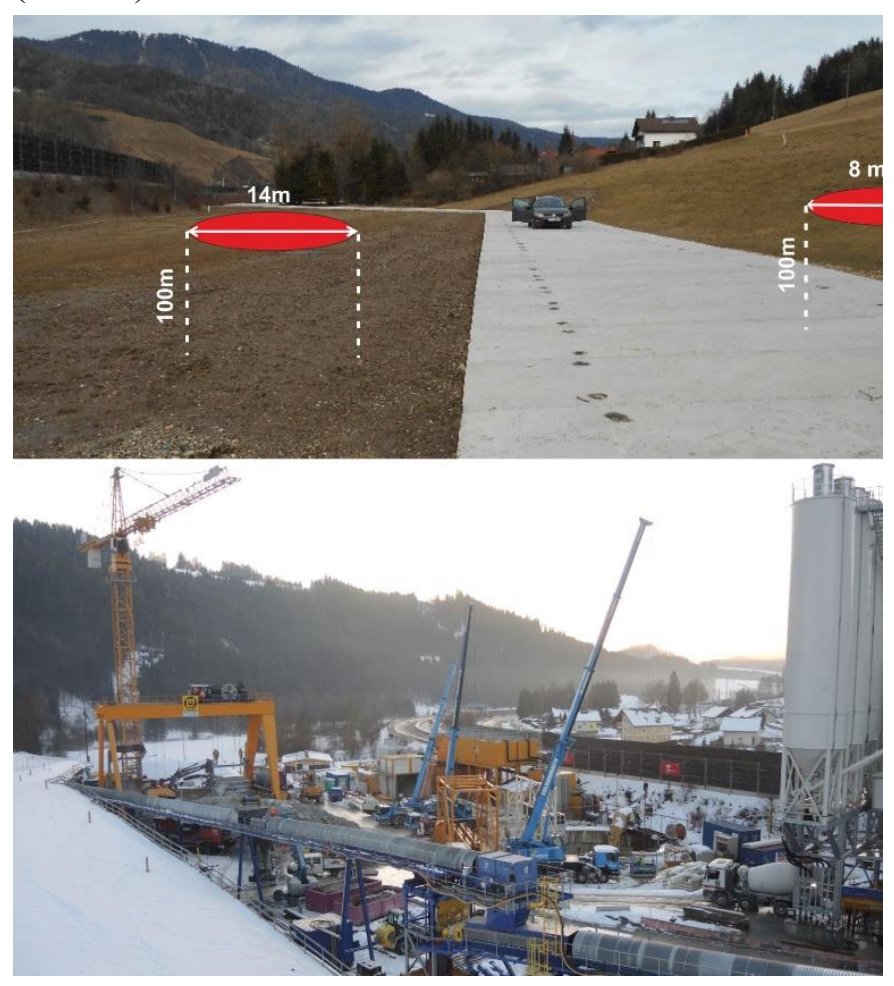

To distribute the construction traffic load, the three pipelines were covered with $6 \mathrm{~m}$ wide concrete load distribution plates (Figure 19 top). Figure 19 bottom shows the area during construction of the $100 \mathrm{~m}$ deep shafts. Automated surfacebased measurements, for example with a total station, are clearly impossible due to the many obstacles which would obstruct the line of sight. The installed subterranean distributed fibre optic measurement system is, thus, the only solution able to permanently monitor the pipelines without interfering with construction work.

\subsection{Results}

The monitoring system has been on-line since July 2016 and is currently configured to measure the fibre loop every hour with a spatial resolution of $1 \mathrm{~m}$. To reduce measurement noise, time averages over $6 \mathrm{~h}$ and spatial averages over $2 \mathrm{~m}$ are calculated. Temperature compensation and strain and curvature calculations are performed with our own integrated algorithms. The results are compared with the warning and alarming threshold values provided by an external consultant. For longitudinal strain these thresholds are $230 \mu \mathrm{m} / \mathrm{m}$ for warning and $460 \mu \mathrm{m} / \mathrm{m}$ for alarming. If these limits are exceeded, e-mail notification is automatically started and counter measures initiated in accordance with the safety plan.

Figure 20 Measured strain values of section 2 since the start of operation

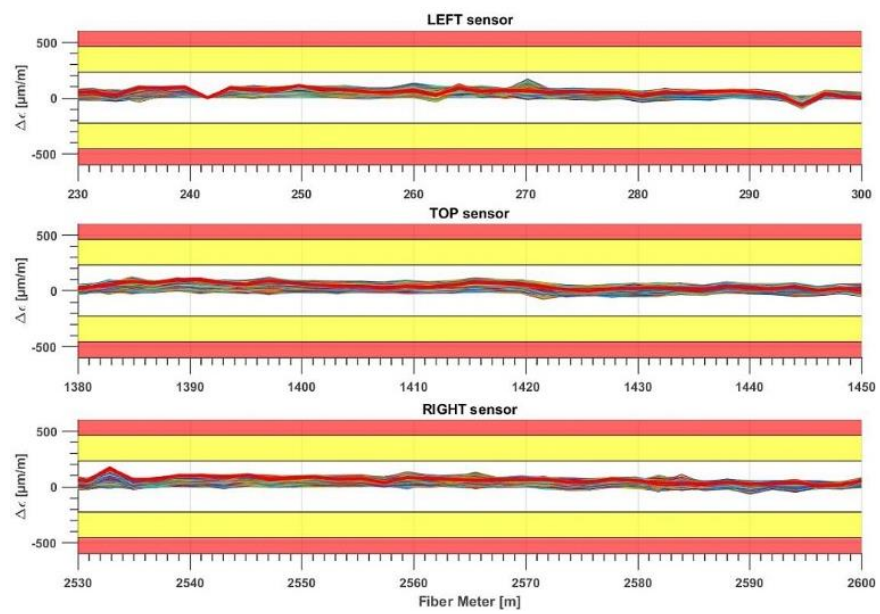

Figure 20 shows the temperature-corrected strains for each sensor line of section 2. The length of this section, which is located at the entrance area of the construction site, is about $70 \mathrm{~m}$. After more than two and a half years of permanent measurements, the strain values lie within a range of $\pm 200 \mu \mathrm{m} / \mathrm{m}$. The issuing of warning or alarming values for this section has, thus, so far not been necessary, unlike other sections as discussed by Klais et al. (2017).

\section{Summary and outlook}

This article describes different distributed fibre optic sensing installations for a large tunnel project. Overall, about $6.5 \mathrm{~km}$ of sensing cables were installed at various construction 
locations. Whilst the monitored objects differ, the main goals are the same at every access point. The measurements must, firstly, not interfere with the construction process since any delay to a tunnelling project is costly. Secondly, the measurements must provide detailed information about the internal behaviour of the object without any information gaps. Thirdly, the measurement systems must be designed to be operated over many decades. Last but not least, the measurements must provide reliable information under harsh conditions and any temperature impact must be corrected.

We have demonstrated the fulfilment of all of these objectives and shown that the installed monitoring systems do indeed increase safety, enable more efficient construction and can contribute to condition-based maintenance during the 150 year operational lifetime of this tunnel.

At the Fröschnitzgraben intermediate access point, two tunnel boring machines (TBMs) are currently starting operations $400 \mathrm{~m}$ below the surface (Figure 21). These machines place precast concrete segments to create the tunnel lining. Equipment of these tunnel lining segments with distributed fibre optic sensing has already been shown by our group at the Koralmtunnel (Monsberger \& Lienhart, 2017; Monsberger et al., 2018) and by Soga et al. (2015). This approach is a potential solution for short and long-term monitoring of precast tunnel lining rings.

Figure 21 Drilling head of the tunnel boring machine in the starting cavern at Fröschnitzgraben

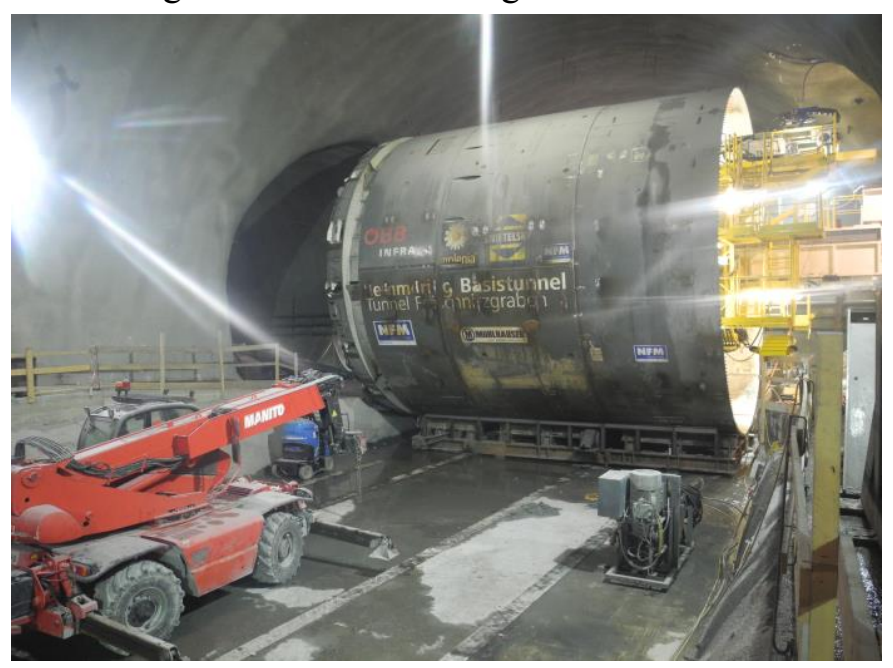

\section{Acknowledgements}

We would like to thank all project partners for their support and funding of the monitoring projects. Special thanks to the Austrian Federal Railways (ÖBB-Infra) namely, Michaela Haberler-Weber, Johannes Fleckl-Ernst, Tobias Schachinger, Frank Klais, Petra Wolf and the project leader of the Semmering Base Tunnel Gerhard Gobiet. Furthermore, we appreciate the collaboration with our other partners, the Institute of Rock Mechanics and Tunnelling of Graz University of Technology (Wulf Schubert and Michael
Henzinger), INSITU (Hartmut Schuller), HBM (Walter Weilinger and Raimund Stefaner), Chris Wrighton, ASFINAG Bau Management GmbH (Michael Steiner) and the Federal Ministry for Transport, Innovation and Technology who all gave valuable input to the different projects, the data interpretation and result communication.

\section{References}

De Battista N, Elshafie M, Soga K, Williamson M, Hazelden G, Hsu YS (2015) Strain monitoring using embedded fibre optic sensors in a sprayed concrete tunnel lining during the excavation of cross-passages. Proc. $7^{\text {th }}$ Int. Conf. on Structural Health Monitoring of Intelligent Infrastructure SHMII, Turin, Italy.

Gobiet G, Nipitsch G, Wagner OK (2017) The Semmering Base Tunnel - Special challenges in construction. Geomechanics and Tunnelling 10(3): 291-297, 10.1002/geot.201700008.

Hartog AH (2018) An Introduction to Distributed Optical Fibre Sensors, CRC Press, Taylor \& Francis Group.

Henzinger R, Schachinger T, Lienhart W, Buchmayer F, Weilinger W, Stefaner R, Haberler-Weber M, Haller EM, Steiner M, Schubert W (2018) Fibre-optic supported measurement methods for monitoring rock pressure. Geomechanics and Tunnelling 11(3): 251-263, 10.1002/geot.201800015

Klais F, Wolf P, Lienhart W (2017) The Grautschenhof contract - Construction of an intermediate access under complex local conditions. Geomechanics and Tunnelling 10(6): 686-693, 10.1002/geot.201700052.

Krohn D, McDougall T, Mendez A (2014) Fiber optic sensors: fundamentals and applications. $4^{\text {th }}$ edition, SPIE Press, Bellingham, Washington, USA.

Monsberger CM, Lienhart W (2017) In-situ Deformation Monitoring of Tunnel Segments using High-resolution Distributed Fibre Optic Sensing. Proc. 8th Int. Conf. on Structural Health Monitoring of Intelligent Infrastructure SHMII-8, Brisbane, Australia: RS1-9

Monsberger CM, Lienhart W, Kluckner A, Wagner L, Schubert W (2018) Continuous strain measurements in a shotcrete tunnel lining using distributed fiber optic sensing. Proc. $9^{\text {th }}$ European Workshop on Structural Health Monitoring (EWSHM), Manchester, United Kingdom.

Monsberger CM, Lienhart W, Moritz B (2018) In-situ assessment of strain behaviour inside tunnel linings using distributed fibre optic sensors. Geomechanics and Tunnelling 11(6): 701-709, 10.1002/geot.201800050.

Moser F, Lienhart W, Woschitz H, Schuller H (2016) Longterm monitoring of reinforced earth structures using distributed fiber optic sensing. Journal of Civil Structural Health Monitoring 6: 321-327, 10.1007/s13349-016-0172-9.

Nipitsch G, Pacher W (2017) The Fröschnitzgraben contract Challenges in shaft sinking, construction logistics and landfill. Geomechanics and Tunnelling 10(6): 678-685, 10.1002/geot.201700053. 
OeGG (2010) NATM - The Austrian Practice of Conventional Tunnelling, Handbook, Austrian Society for Geomechanics, Salzburg, Austria.

OeGG (2014) Geotechnical Monitoring in Conventional Tunnelling. Handbook, Austrian Society for Geomechanics, Salzburg, Austria.

Schuller H, Riepler F, Schachinger T (2014) Preliminary works for the new Semmering Base Tunnel - geotechnical monitoring of slope stabilization measures and earth retaining structures. Geomechanics and Tunnelling 7(4): 339-352, 10.1002/geot.201400028.

Soga K, Kwan V, Pelecanos L, Rui Y1, Schwamb T, Seo H, Wilcock M (2015) The Role of Distributed Sensing in Understanding the Engineering Performance of Geotechnical Structures. Proc. XVI ECSMGE Geotechnical Engineering for Infrastructure and Development: 1-48. 10.1680/ecsmge.60678.

Wagner OK, Haas D, Druckfeuchter H, Schachinger T (2015) The challenges of contract SBT1.1 "Tunnel Gloggnitz". Geomechanics and Tunnelling 8(6): 554-567, 10.1002/geot.201500038.

Wieland G, Prall K, Lenz G, Schachinger T, Gobiet G (2018) Semmering Base Tunnel - Design and construction of the shaft head caverns under difficult conditions. Geomechanics and Tunnelling 11(5): 462-470, 10.1002/geot.201800040 